\section{Cutaneous horn malignant melanoma}

\author{
Haruto Nishida, ${ }^{1}$ Tsutomu Daa, ${ }^{1}$ \\ Kenji Kashima, ${ }^{1}$ Motoki Arakane, ${ }^{1}$ \\ Hiromitsu Shimada, ${ }^{2}$ Mizuki Goto, ${ }^{2}$ \\ Yoshitaka Kai, ${ }^{2}$ Yutaka Hatano, ${ }^{2}$ \\ Osamu Okamoto, ${ }^{2}$ Shigeo Yokoyama ${ }^{1}$ \\ Departments of 'Diagnostic Pathology \\ and 'Dermatology, Faculty of Medicine, \\ Oita University, Yufu, Japan
}

\section{Abstract}

A 73-year-old Japanese woman presented with cutaneous horn on the right cheek. The resected tumor was $9 \mathrm{~mm}$ in diameter, with 14 mm protrusion, and showed exophytic growth with marked papillomatosis. Histopathology showed proliferation of atypical melanocytes with melanin pigments in the epidermis and dermis under the cutaneous horn. These cells were confined to the base of the cutaneous horn, and did not spread to the surrounding epidermis. The final diagnosis was cutaneous horn malignant melanoma. This pathological entity is considered a specific form of verrucous melanoma, and might be added to the list of cutaneous horn-forming lesions.

\section{Introduction}

Cutaneous horn is a conical- or cylindricalshaped excessive hyperkeratosis of variable size (few millimeters to several centimeters). ${ }^{1}$ It is a clinical diagnosis, and includes various benign and malignant lesions. ${ }^{1-6}$ Many malignant lesions arise in sun-exposed areas such as head, neck and upper extremities, most of which are actinic keratosis, Bowen's disease or squamous cell carcinoma. ${ }^{4}$ However, Cristobal et al. ${ }^{7}$ and Ermertcan et al. ${ }^{8}$ reported extremely rare variants of malignant melanoma (MM) with horn formation termed cutaneous horn MM. Herein we report the third case of cutaneous horn MM and review of the literature.

\section{Case Report}

A 73-year-old Japanese woman presented with a black cutaneous horn on the right cheek. The horn appeared about 10 years ago, and had since increased in size. The past and family histories were not significant.
Macroscopic examination of the lesion showed a well-circumscribed, round and hard black cutaneous horn, measuring $9 \mathrm{~mm}$ in diameter protruding $14 \mathrm{~mm}$ from the skin surface (Figure 1A). There was no palpable cervical lymphadenopathy. The clinical diagnosis was seborrheic keratosis with horn formation. The differential diagnosis included basal cell carcinoma and actinic keratosis/squamous cell carcinoma. The lesion was surgically resected with a small safety margin.

Microscopic examination of the resected specimen showed a cutaneous horn composed of excessive compact hyperkeratosis with melanin pigments and pigment-laden degenerated macrophages in sun-damaged skin with solar elastosis (Figure 1B). The epidermis was also hyperplastic and markedly elevated with exophytic growth, but keratinocytes showed no atypia (Figure 2A). Proliferation of atypical tumor cells was noted in the epidermis, especially in the basal layer, with invasion of the upper dermis by melanophages and lymphocytes (Figure 2A). Tumor cells were also confined to the base of the cutaneous horn without lentiginous or pagetoid spreading to the surrounding epidermis. They were spindle or rounded epithelioid cells with prominent nucleoli and melanin pigments (Figure 2B). Several mitotic tumor cells were also observed. Immunohistochemically, the tumor cells were strongly positive for Melan A/MART-1, HMB45 and S-100 protein, but negative for pan-keratin. Based on these findings, the final diagnosis was cutaneous horn MM. The longest dimension of Breslow's thickness was $10 \mathrm{~mm}$ and Clark's level was level III. According to the TNM classification, the tumor was classified stage IIB (pT4aN0M0).

Additional resection with $1 \mathrm{~cm}$ margin, sentinel lymph node dissection and postoperative chemotherapy (DAV-feron therapy: dacarbazine; nimustine; vincristine; interferon- $\beta$ ) were applied after the diagnosis. Examination of the sentinel lymph nodes identified no metastasis. No local recurrence or distant metastasis has been observed during the last 4 years of follow-up.

\section{Discussion}

Cutaneous horn is a clinical diagnosis observed in both benign and malignant conditions. About $40 \%$ of cutaneous horns are part of malignant lesions, especially actinic keratosis, Bowen's disease and squamous cell carcinoma (Table 1). However, non-squamous epithelial and even mesenchymal tumors, such as Paget's disease, ${ }^{9}$ metastatic renal cell carcinoma,${ }^{10}$ Kaposi's sarcoma and pyogenic granuloma, ${ }^{11,12}$ rarely form cutaneous horn.

MM with cutaneous horn is an extremely
Correspondence: Haruto Nishida, Department of Diagnostic Pathology, Faculty of Medicine, Oita University, 1-1, Idaigaoka, Hasama-machi, Yufu City, 879-5593, Japan.

Tel. +81.975.865.683 - Fax: +81.975.865.686

E-mail: nharuto@oita-u.ac.jp

Key words: skin, cutaneous horn, malignant melanoma, verrucous malignant melanoma.

Contributions: the authors contributed equally.

Conflict of interests: the authors declare no potential conflict of interests.

Received for publication: 3 August 2013

Revision received: 16 September 2013.

Accepted for publication: 21 September 2013.

This work is licensed under a Creative Commons Attribution NonCommercial 3.0 License (CC BYNC 3.0).

(O)Copyright H. Nishida et al., 2013

Licensee PAGEPress, Italy

Dermatology Reports 2013; 5:e3

doi:10.4081/dr.2013.e3

rare variant of $\mathrm{MM}$, and to date two cases have been reported. ${ }^{7,8} \mathrm{MM}$ includes various clinical subtypes, ${ }^{13}$ but cutaneous horn MM was not described in any textbooks probably because of its rarity. $\mathrm{MM}$ is commonly classified into four major subtypes: lentigo maligna melanoma; superficial spreading melanoma; nodular melanoma and acral lentiginous melanoma. Other variants are described in the WHO classification, which includes amelanotic melanoma, mucosal melanoma, subungual melanoma, ulcerated melanoma and verrucous melanoma. ${ }^{13}$ Among them, the latter is probably similar to cutaneous horn MM. In the majority of MM, the epidermis is often thin and occasionally ulcerated, but epidermal hyperplasia with hyperkeratosis is occasionally seen in MM, of which MM with excessive hyperkeratosis is called verrucous melanoma. In general, verrucous melanoma presents as a hyperkeratotic, pigmented and elevated lesion, which may be macroscopically misdiagnosed as seborrheic keratosis. However, verrucous melanoma is a plateau- or dome-shaped lesion with verrucous keratotic surface in contrast to the conical or cylindrical lesion of cutaneous horn MM. ${ }^{14,15}$ At the point of excessive hyperkeratosis, cutaneous horn MM seems to be a specific form of verrucous melanoma, in which the morphology of excessive hyperkeratosis is just different from each other.

Occasionally, hypermelanotic nevi show similar changes in the stratum corneum. This lesion is distinguishable based on the absence of cytologic atypia. ${ }^{16}$ There are two reports of cutaneous horn-forming MM, ${ }^{7,8}$ and our case is 


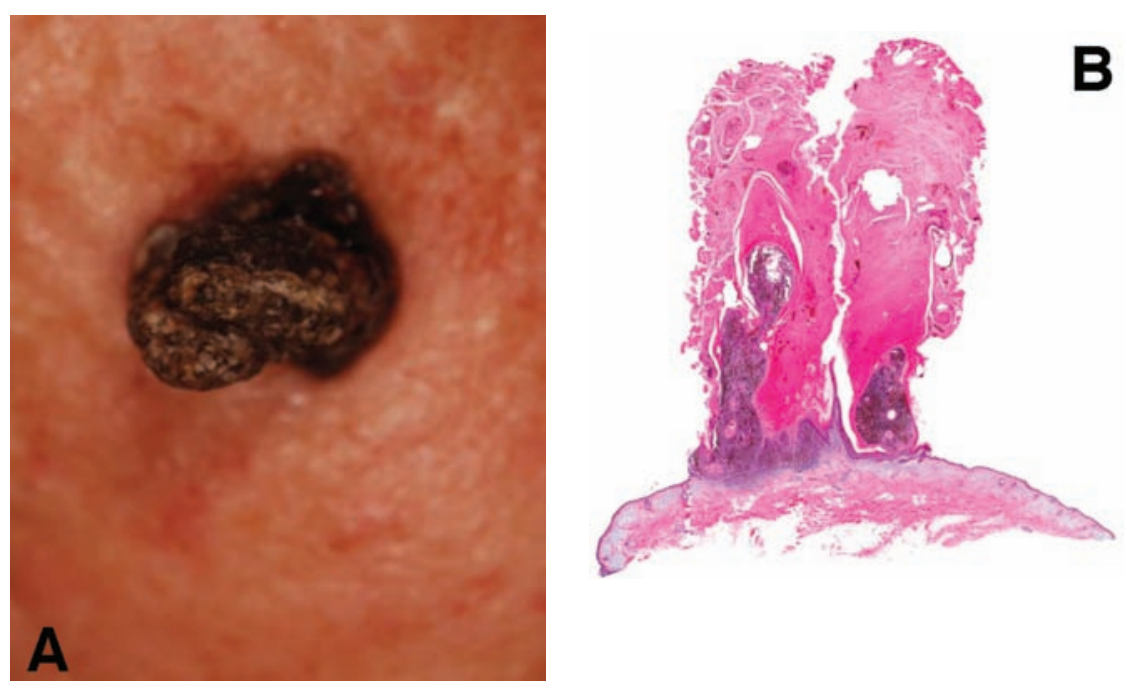

Figure 1. The lesion was a black cutaneous horn on the right cheek (A). The resected specimen showed a cutaneous horn with compact growth of tumor cells in the underlying epidermis and upper dermis, with marked solar elastosis (B, hematoxylin-eosin staining, loupe).
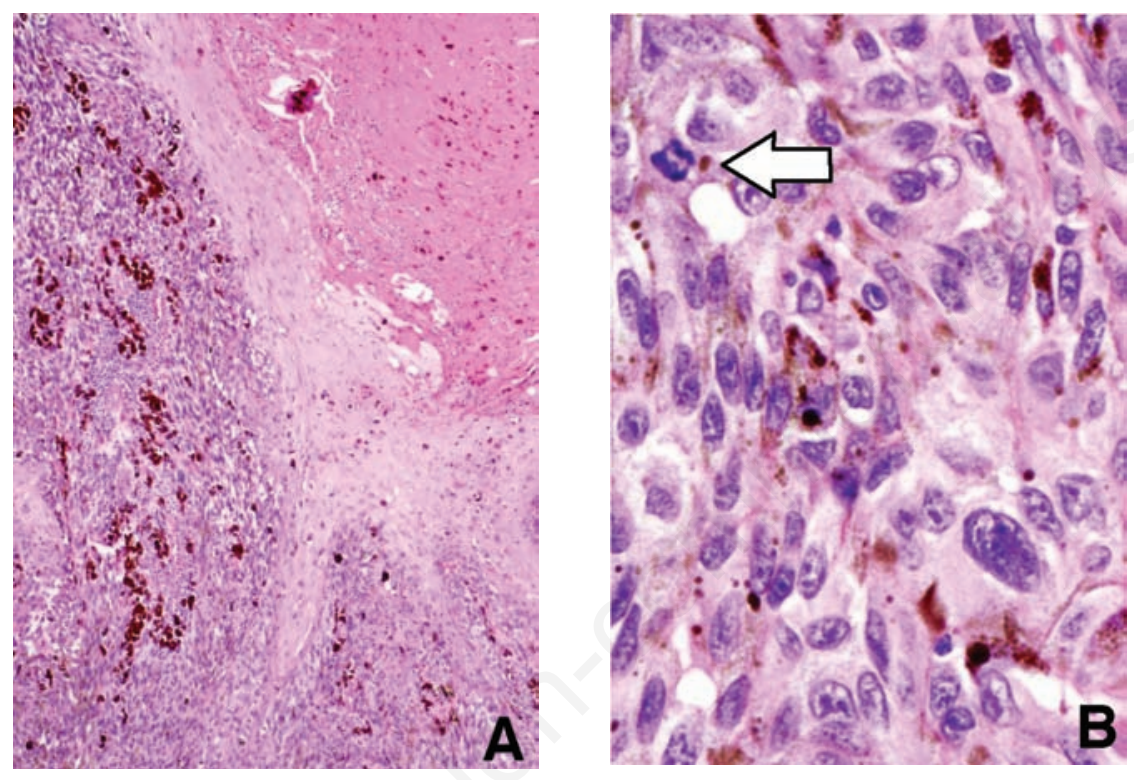

Figure 2. The epidermis showed acanthosis, and atypical cells invaded the epidermis. Keratinocytes show no atypia (A, hematoxylin-eosin staining, 20x). Note the proliferation of spindle-to-round epithelioid atypical cells, with melanophages, at the base of the cutaneous horn. Arrow: mitotic tumor cell (B, hematoxylin-eosin staining, 40x). close to the first one. ${ }^{7}$ The first case showed an equally conical, hyperkeratotic lesion with highly atypical melanocytes. The tumor cells were confined to the base of cutaneous horn, but they grew asymmetrically. Their case had also the discrepancy between Breslow's thickness and Clark's level. Although the second case involved lentigo MM with cutaneous horn, ${ }^{8}$ cutaneous horn was composed of atypical melanocytes. Atypical melanocytes showing pagetoid proliferation around cutaneous horn are structurally different from those described in our case.

The mechanism of development of cutaneous horn remains unclear. Since cutaneous horn is almost always found in sun-exposed areas such as face, neck, scalp and extremities, long-term sunlight irritation is the most likely etiology. Another possible etiology is persistent inflammatory process, ${ }^{17}$ or overgrowth of blood vessels with abundant bloodstream. $^{18,19}$

From the viewpoint of cutaneous horn, the risk factors of malignancy include large size, wide base relative to height, tenderness, advanced age and male sex. ${ }^{4}$ Although MM probably has good prognosis with early stage in general, the most cited predictors of poor prognosis are Breslow's thickness, Clark' levels of invasion, ulceration, rate of mitosis, lymphovascular invasion, location, and gender. ${ }^{13}$ In the cutaneous horn MM, however, marked exophytic growth causes a discrepancy between Breslow's thickness and Clark's level, increased Breslow's thickness for low Clark's level. Cristobal's and the present case shared common pathological findings in addition to the horn formation; including confinement of tumor cells to the base of the cutaneous horn without spread to the surrounding tissue. The prognosis of cutaneous horn MM may be based on the clinical stage, as judged by Breslow's thickness not to underestimate, but there is a need for study in the future.

Table 1. Reported cases of benign and malignant lesions with cutaneous horn.

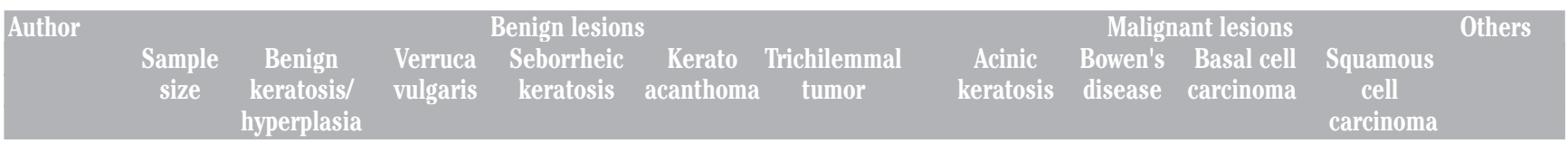

\begin{tabular}{|c|c|c|c|c|c|c|c|c|c|c|c|}
\hline Mehregan² & 100 & 0 & 30 & 56 & 0 & 0 & 0 & 2 & 0 & 9 & 3 \\
\hline Bart et al. ${ }^{1}$ & 37 & 6 & 0 & 14 & 0 & 0 & 8 & 0 & 0 & 8 & 1 \\
\hline Schosser et al. ${ }^{3}$ & 230 & 2 & 52 & 37 & 2 & 1 & 86 & 1 & 3 & 41 & 5 \\
\hline Yu et al. ${ }^{4}$ & 643 & 150 & 100 & 135 & 3 & 4 & 123 & 26 & 0 & 101 & 1 \\
\hline Mantese et al.5 & 222 & 30 & 29 & 20 & 0 & 3 & 114 & 0 & 1 & 15 & 10 \\
\hline Copcu et al. ${ }^{6}$ & 11 & 2 & 0 & 2 & 0 & 0 & 4 & 0 & 1 & 2 & 0 \\
\hline Total (\%) & $\begin{array}{l}1243 \\
(100)\end{array}$ & $\begin{array}{c}190 \\
(15.3)\end{array}$ & $\begin{array}{c}211 \\
(17.0)\end{array}$ & $\begin{array}{c}264 \\
(21.2)\end{array}$ & $\begin{array}{c}5 \\
(0.4)\end{array}$ & $\begin{array}{c}8 \\
(0.6)\end{array}$ & $\begin{array}{c}335 \\
(27.0)\end{array}$ & $\begin{array}{c}29 \\
(2.3)\end{array}$ & $\begin{array}{c}5 \\
(0.4)\end{array}$ & $\begin{array}{c}176 \\
(14.2)\end{array}$ & $\begin{array}{c}20 \\
(1.6)\end{array}$ \\
\hline
\end{tabular}




\section{Conclusions}

In this report, we describe a patient with an unusual clinical presentation of MM, masquerading as a cutaneous horn. Cutaneous horn is a macroscopic diagnosis only, and it is important to determine the nature of the underlying lesion by histopathological examination. Although various benign and malignant lesions form cutaneous horn, MM, especially if pigmented, might be added to the differential diagnosis.

\section{References}

1. Bart RS, Andrade R, Kopf AW. Cutaneous horns. A clinical and histopathologic study. Acta Derm Venereol 1968;48:507-15.

2. Mehregan AH. Cutaneous horn: a clinicopathologic study. Dermatol Dig 1965;4:4554 .

3. Schosser RH, Hodge SJ, Gaba CR, Owen LG. Cutaneous horns: a histopathologic study. South Med J 1979;72:1129-31.

4. Yu RC, Pryce DW, Macfarlane AW, Stewart TW. A histopathological study of 643 cuta- neous horns. Br J Dermatol 1991;124:44952.

5. Mantese SA, Diogo PM, Rocha A, et al. Cutaneous horn: a retrospective histopathological study of 222 cases. An Bras Dermatol 2010;85:157-63.

6. Copcu E, Sivrioglu N, Culhaci N. Cutaneous horns: are these lesions as innocent as they seem to be? World J Surg Oncol 2004;2:18.

7. Cristóbal MC, Urbina F, Espinoza A. Cutaneous horn malignant melanoma. Dermatol Surg 2007;33:997-9.

8. Ermertcan AT, Eskıızmır G, Gençoğlan G, et al. Lentigo malignant melanoma presenting with cutaneous horn. Dermatol Surg 2010;36:1759-62.

9. Dabski K, Stoll HL Jr. Paget's disease of the breast presenting as a cutaneous horn. J Surg Oncol 1985;29:237-9.

10. Peterson JL, McMarlin SL. Metastatic renal-cell carcinoma presenting as a cutaneous horn. J Dermatol Surg Oncol 1983;9:815-8.

11. Gibbs RC, Hyman AB. Kaposi's sarcoma at the base of cutaneous horn. Arch Dermatol 1968;98:37-40.

12. Findlay RF, Lapins NA. Pyogenic granuloma simulating a cutaneous horn. Cutis
1983;31:610-2.

13. de Vries E, Bray F, Coebergh JW, et al. Malignant melanoma. In: Philip EL, Gunter B, David W, Alain S, eds. World Health Organization classification of tumours. Pathology and genetics of tumours of the skin. Lyon: IARC Press; 2006. pp 50-65.

14. Kuehnl-Petzoldt C, Berger H, Wiebelt $\mathrm{H}$. Verrucous-keratotic variations of malignant melanoma: a clinicopathological study. Am J Dermatopathol 1982;4:403-10.

15. Steiner A, Konrad K, Pehamberger H, Wolff K. Verrucous malignant melanoma. Arch Dermatol 1988;124:1534-7.

16. Cohen LM, Bennion SD, Johnson TW, Golitz LE. Hypermelanotic nevus: clinical, histopathologic, and ultrastructural features in 316 cases. Am J Dermatopathol 1997;19:23-30.

17. Gerding H, Hailemariam S, Ohlinger W, Timmermann M. Cutaneous horn of the eyelid in a 4-year-old child. Klin Monbl Augenheilkd 2010;227:319-20.

18. Taylor JA. Penile horn. Trans Am Assoc Genitourin Surg 1945;37:101-8.

19. Yang JH, Kim DH, Lee JS, et al. A case of cutaneous horn originating from keratoacanthoma. Ann Dermatol 2011;23:89-91. 